\title{
Aspectos Moleculares en la Formación de la Cara y del Paladar
}

\author{
Molecular Basis on the Face and Palate Development \\ María Angélica Montenegro \& Mariana Rojas
}

MONTENEGRO, M. A. \& ROJAS, M. Aspectos moleculares en la formación de la cara y del paladar. Int. J. Morphol., 23(2):185194, 2005.

RESUMEN: En mamíferos, la adhesión y fusión de los procesos faciales y palatinos, son mecanismos esenciales en el desarrollo del paladar primario y secundario. La falla de cualquiera de estos procesos trae como consecuencia la formación de labio leporino o fisura palatina. En ambos casos, los procesos opuestos adhieren a través de desmosomas para formar una lámina epitelial media la cual desaparece por transformación epitelio-mesenquimática. La apoptosis ocurre sólo en las células del periderma.

En el paladar secundario, estos procesos están regulados por TGFß-3, pero este factor no está presente en los procesos maxilares o nasales que forman el paladar primario, por lo cual en la formación del labio actuarían otros factores tales como Shh (sonic hedgehog) y BMP (proteína morfogenética de hueso), que ya se ha demostrado están involucrados en la fusión del labio de pollo.

PALABRAS CLAVE: Paladar de ratón; Labio de pollo; TGFß-3; Shh; Transformación epitelio-mesenquimática.

\section{INTRODUCCIÓN}

El desarrollo de la cara y paladar de los mamíferos son eventos complejos que se alteran frecuentemente. En la especie humana dan como resultado malformaciones como la fisura palatina o el labio leporino. En animales de laboratorio como el ratón, se pueden inducir estos defectos fácilmente por la acción de diferentes teratógenos.

La fisura palatina y el labio leporino, son malformaciones relativamente frecuentes en la especie humana. Las incidencias encontradas en distintas partes del mundo, indican en general, un importante componente racial de susceptibilidad, independiente de la región geográfica de residencia. Estudios en poblaciones amerindias revelan también altas incidencias relacionados con el origen oriental de estas poblaciones, donde también se registran altas incidencias poblacionales (Tabla I) (Palomino et al., 1997).

Sudamérica, es desde un punto de vista étnico, una mezcla amerindia-europea prematuramente establecida y con posteriores migraciones africanas. Se observan mayores in-
Tabla I. Incidencia de fisuras labio-palatinas según Palomino et al., 1997.

- Poblaciones orientales (China-Japón) 1: $700 \mathrm{RNV}$

- Poblaciones de origen negro (USA - África) 1: 2500 RNV

- Poblaciones caucásicas (Europeas) 1: 1000 RNV

- Poblaciones indígenas americanas 1: $150 \mathrm{RNV}$

- Chile Clínicas privadas de Santiago 1: 1000 RNV

- Chile Hospitales públicos de Santiago 1: 650 RNV

cidencias en países del área andina y menores en países atlánticos, relacionado con la composición étnica de las poblaciones.

En Chile se ha encontrado una relativa alta incidencia (1 cada 620 RNV) y mayor en las poblaciones que tienen un componente indígena más elevado. Así, en maternidades de clínicas privadas de Santiago, que tienen bajo porcentaje de indigenicidad, tienen una incidencia de fisuras de 1 en 1000 RNV comparado con el de las maternidades públicas, donde el grado de mezcla indígena es alto, y la incidencia de fisuras es más alta 1,8 en 1000 RNV (Fig. 1). 


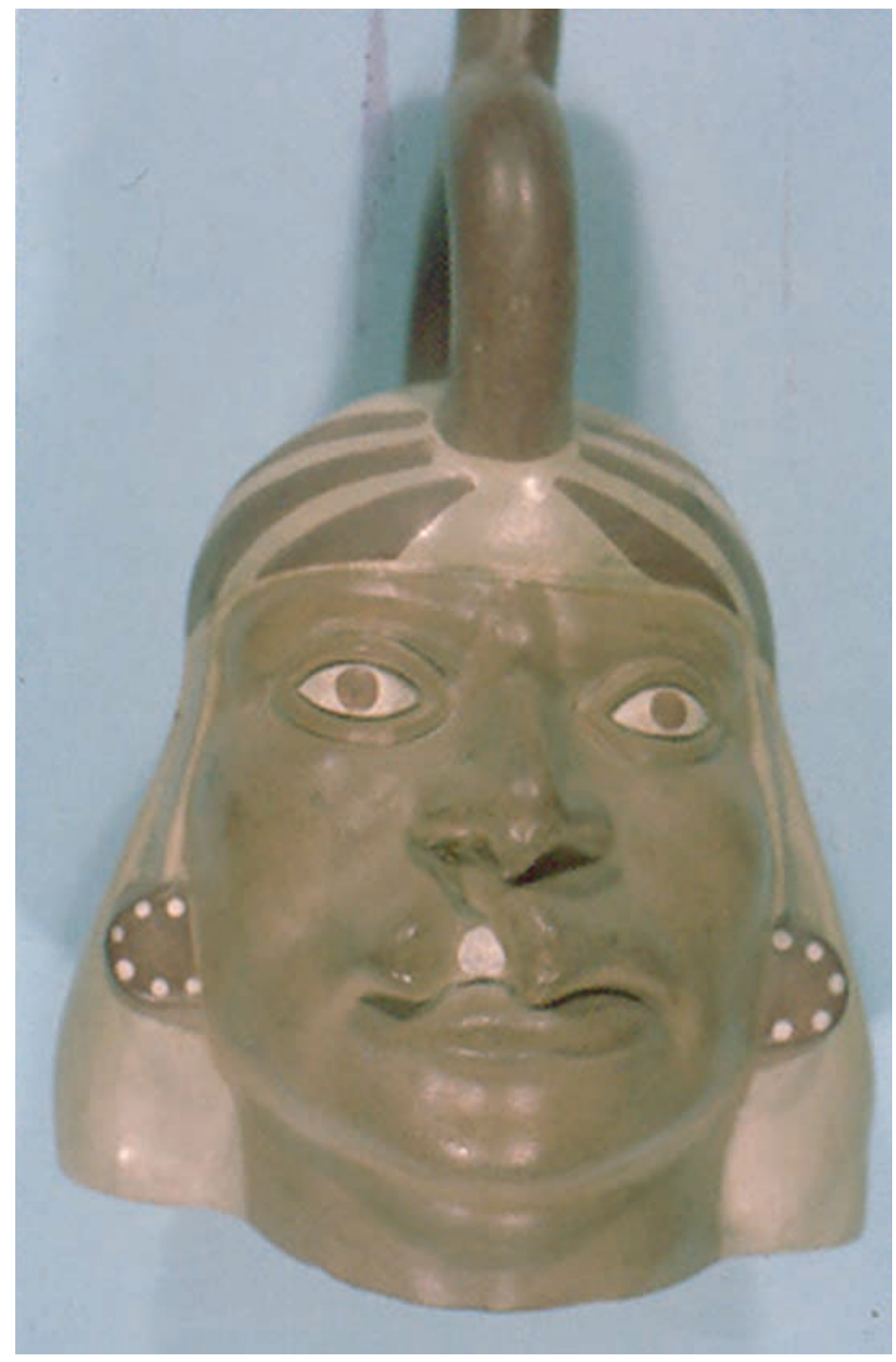

Fig. 1. Cerámica de la antigua cultura mochica del Norte de Perú, representando un labio leporino

La formación del paladar de ratón, es un buen modelo para analizar mecanismos fundamentales que son comunes en muchas estructuras de un organismo complejo como son los mamíferos. Se desarrolla relativamente tarde durante la embriogénesis y puede ser disecado y cultivado en medios químicamente definidos, donde se fusiona normalmente de manera similar a lo que ocurre in vivo.

Desarrollo normal del paladar secundario. En el desarrollo normal del paladar, las células mesenquimáticas provenientes de la cresta neural migran hacia la cavidad oral primitiva donde, en asociación con el epitelio ectodérmico cráneo-faríngeo forman los procesos palatinos, los procesos faciales y los arcos faríngeos.

El paladar se forma a partir de 3 esbozos: el paladar primario derivado de los procesos nasales medios y los procesos palatinos del paladar secundario. Estos crecen y se fusionan entre sí y con el tabique nasal.

Los procesos palatinos, bilaterales, emergen desde los procesos maxilares del primer arco branquial, en el día 12 de gestación en el ratón y a las 6 semanas (día 45) en el embrión humano. Inicialmente, los procesos palatinos crecen verticalmente a ambos lados de la lengua, pero en un momento preciso del desarrollo (14 días en el ratón y 7 semanas o 52 días en humano), se reorientan rápidamente a una posición horizontal sobre el dorso de la lengua para encontrarse en la línea media (Ferguson, 1988; 1994).

En las 12 horas siguientes, los epitelios medios de ambos procesos, contactan, adhieren y forman una lámina epitelial media, que desaparece rápidamente para establecer la confluencia mesenquimática y completar la fusión entre ambos procesos palatinos (Figs. 2 y 3 ).

En esta etapa, el epitelio palatino medio es biestratificado con una capa basal de células cúbicas y una capa de células superficiales aplanadas del periderma.

La mayoría de las células del periderma de la zona media (superficiales), experimentan apoptosis (muerte celular programada) y son eliminadas antes de la adhesión. Luego, se forman desmosomas entre las células basales de los procesos opuestos, lo que facilita la formación de la lámina epitelial media (Nawshad et al., 2004).

A medida que el paladar y la cabeza crecen, principalmente por expansión en altura, la lámina epitelial media se adelgaza a una sola capa de células y se rompe en pequeños islotes. Al mismo tiempo, la lámina basal desaparece y las células epiteliales extienden filopodios hacia el mesénquima subyacente (Hay, 1995).

Este proceso es seguido por una transformación de la lámina epitelial y de los islotes en células mesenquimáticas que se elongan y migran hacia el tejido conectivo, permitiendo la continuidad del tejido mesenquimático en el día 15 de gestación en ratón y durante la $9^{\mathrm{a}}$ semana en el embrión humano.

Experimentos de separación y recombinación de capas celulares in vitro han demostrado que este proceso es resultado de una serie de interacciones 

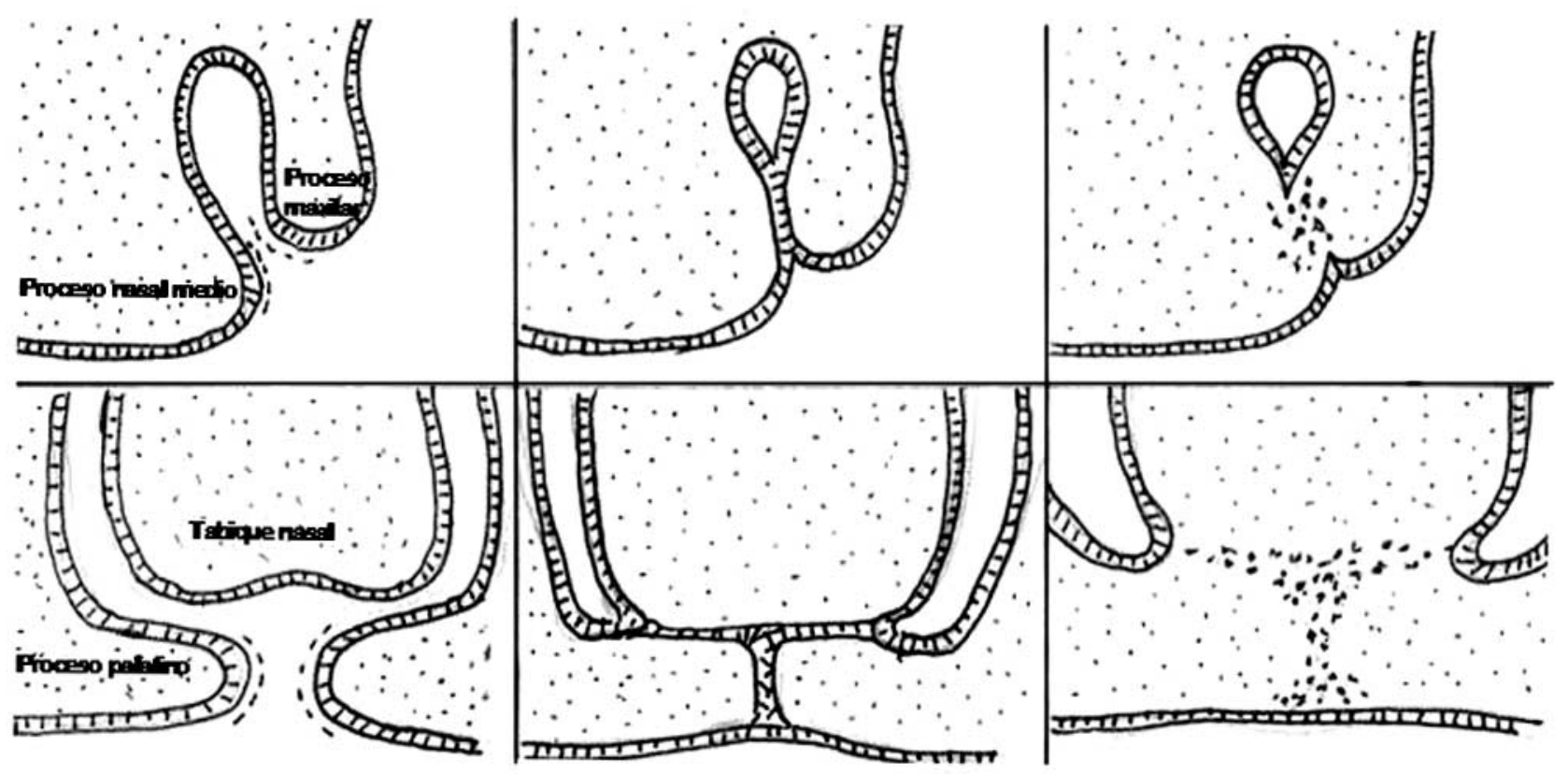

Fig. 2. Esquemas comparativos de la morfogénesis del labio superior y la del paladar. Después de la eliminación de las células peridérmicas, los procesos maxilares y nasales medios se fusionan formando una lámina epitelial media, la que luego se transforma en mesénquima. En una etapa posterior, los procesos palatinos se fusionan entre sí y con el tabique nasal, originando una lámina epitelial media que se transforma en mesénquima. (Modificado de Sun et al., 2000)

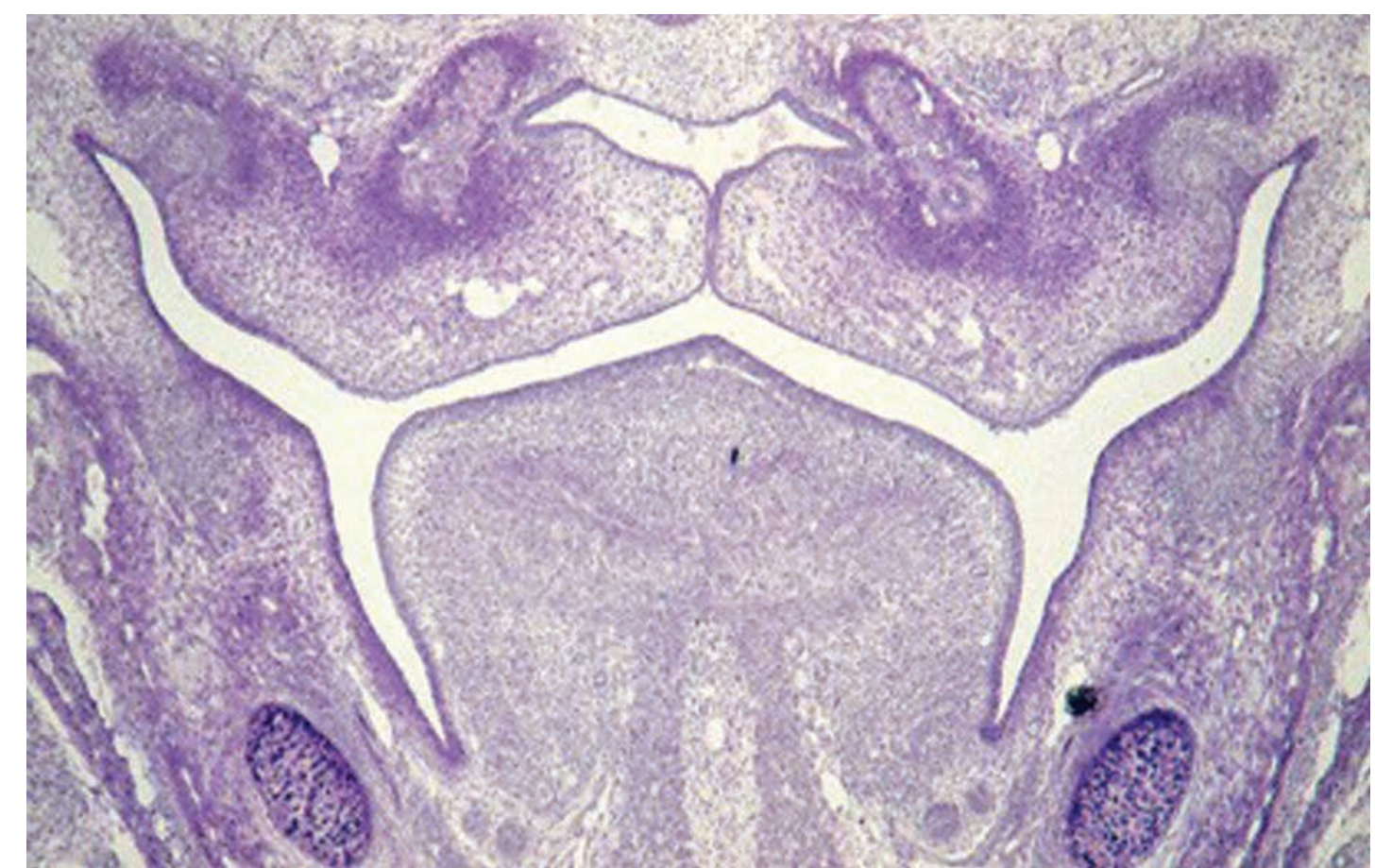

Fig. 3. Corte coronal de cabeza de embrión de ratón que muestra la adhesión de los procesos palatinos. Tinción: H-E. 40X

secuenciales entre el epitelio y el mesénquima subyacente, mediadas por distintas moléculas que pueden ser diferencialmente afectados por los teratógenos que producen fisura palatina (Ferguson).
La palatogénesis es un proceso complejo que involucra la participación de muchos genes que codifican factores de crecimiento, sus receptores y factores de transcripción. 
En aves, los procesos palatinos bilaterales emergen desde los procesos maxilares, pero en vez de crecer verticalmente, como en los mamíferos, crecen horizontalmente sobre el dorso de la lengua. Los procesos palatinos se aproximan, contactan, pero sus epitelios no adhieren, no se fusionan, ni se produce muerte celular, sino que se queratinizan, manteniéndose una fisura palatina natural (Fig. 4). Algunos reptiles como las lagartijas, tienen un desarrollo similar al de las aves y una fisura palatina natural (Ferguson et al., 1984).

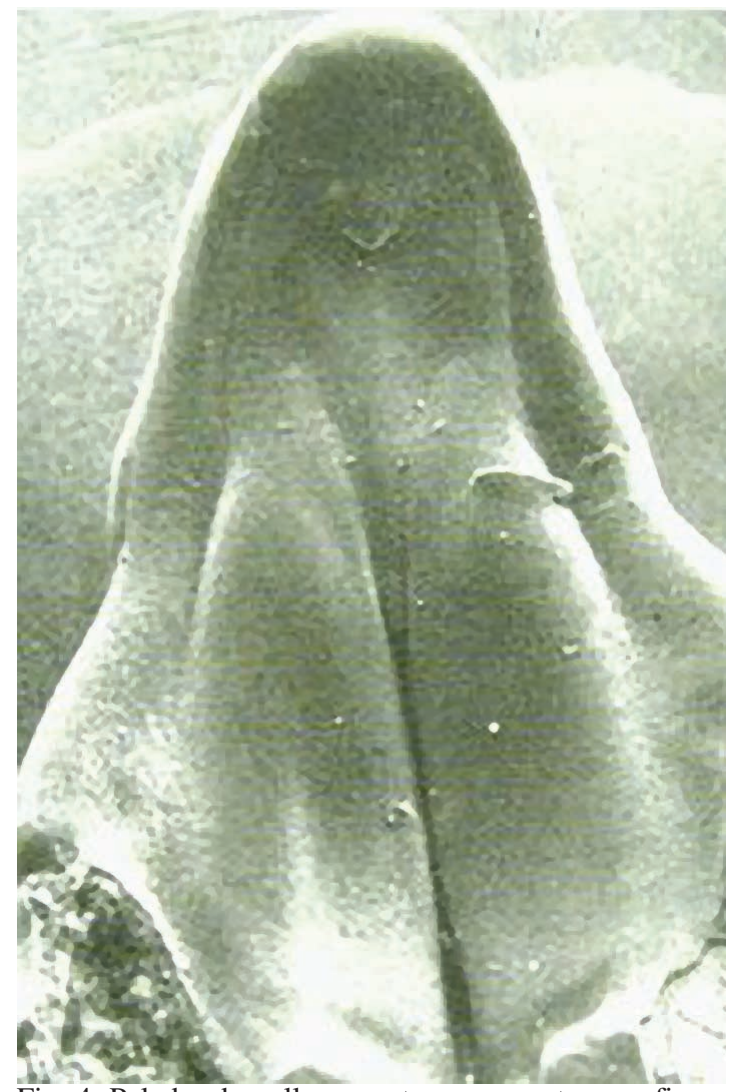

Fig. 4. Paladar de pollo neonato que muestra una fisura palatina natural.

Otro grupo de reptiles como cocodrilos sin embargo, tienen un paladar secundario fusionado, similar al de los mamíferos (Fig. 5). En estos animales, los procesos palatinos bilaterales emergen desde los procesos maxilares, y en los $4 / 5$ anteriores del paladar crecen horizontalmente sobre el dorso de la lengua. En el quinto posterior del paladar, crecen verticalmente, se remodelan a una posición horizontal y la fusión ocurre similar a los mamíferos.

Anfibios y otros reptiles como ciertas especies de tortugas y culebras, solo tienen un paladar primario algo más desarrollado, originado de los procesos nasales medios, for-

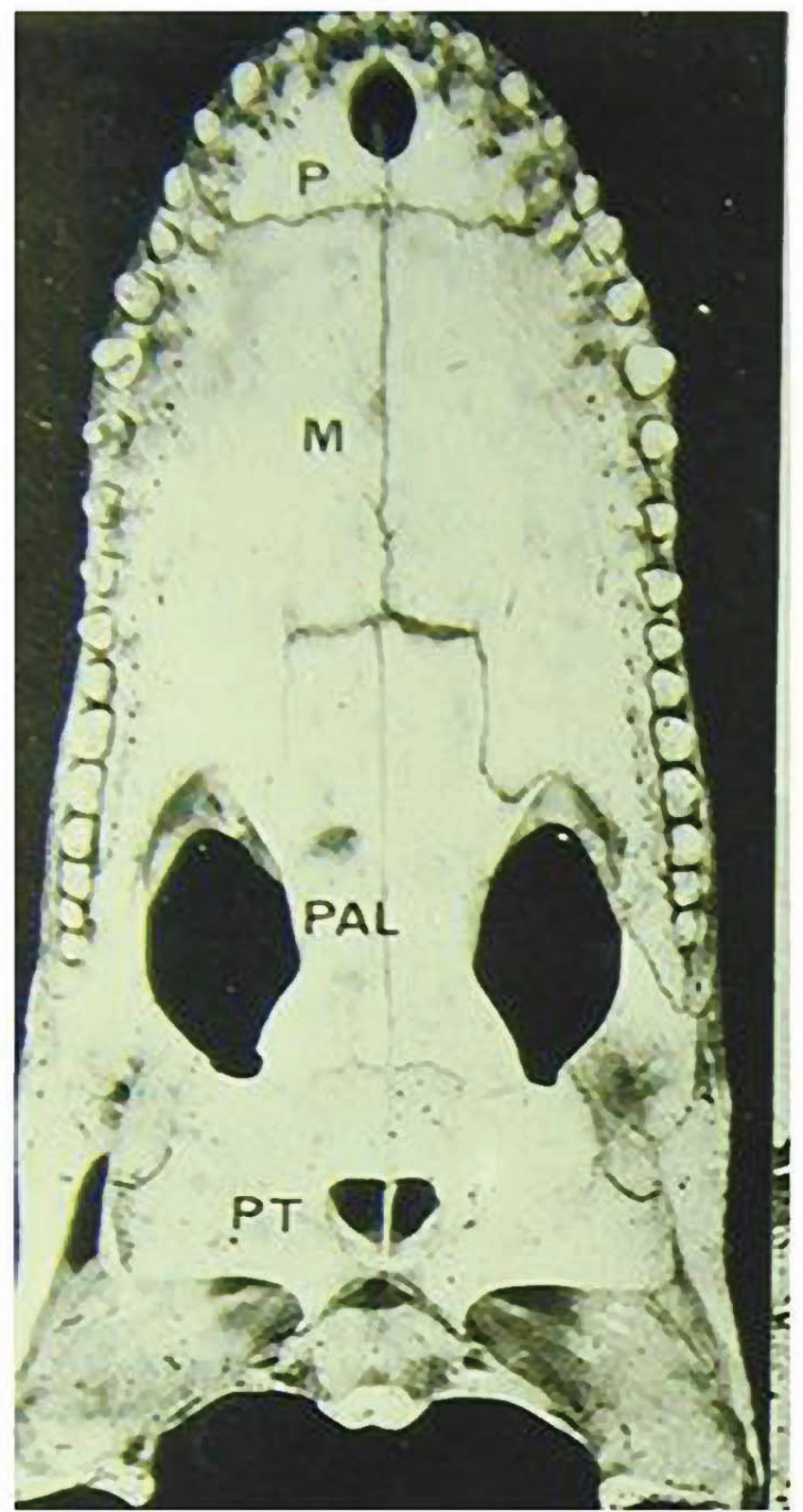

Fig. 5. Cráneo de cocodrilo que muestra el paladar primario y secundario

mando el techo de la boca. El desarrollo del paladar secundario está ausente en vertebrados inferiores, incluyendo peces. Por lo tanto, filogenéticamente la fisura palatina es ancestral al paladar fusionado.

En todos los vertebrados, el epitelio nasal se diferencia en un epitelio cilíndrico, seudoestratificado ciliado y el epitelio oral en uno escamoso estratificado.

El fenotipo del epitelio medio, sin embargo, difiere en las distintas especies: en mamíferos forma una lámina epitelial media, la cual desaparece por transformación epi- 
telio-mesenquimática, en aves se queratiniza sin fusionarse y en cocodrilos las células epiteliales migran hacia la parte nasal del paladar.

En el desarrollo del paladar secundario de los mamíferos, se pueden evidenciar tres etapas críticas (Palomino \& Montenegro, 2002):

- Origen y migración de las células de la cresta neural hacia la región facial y faríngea, lo que ocurre entre los 25 y 28 días de gestación en embrión humano.

- Horizontalización de los procesos palatinos desde una posición vertical a ambos lados de la lengua a una posición horizontal sobre ella.

- Adhesión y fusión de los procesos palatinos entre sí, con el paladar primario y el tabique nasal.

Desarrollo normal de la cara y paladar primario. En todos los vertebrados, la cara se forma de manera similar, a partir de los procesos maxilares, nasales medios y nasales laterales, los cuales contactan y se fusionan formando una lámina epitelial media, que desaparece para establecer la confluencia del tejido mesenquimático (Figs. 2 y 6).

Los eventos moleculares subyacentes a la morfogénesis de la cara han sido poco estudiados en mamíferos, y sólo en los últimos años se han analizado utilizando la cara del pollo como modelo (Sun et al., 2000).

En el pollo, la fusión del labio es similar a la del paladar de ratón. También hay apoptosis de las células superficiales y la fusión involucra 2 eventos:

- Adherencia de los epitelios opuestos con formación de desmosomas

- Transformación epitelio-mesénquima (TEM) de la lámina epitelial y confluencia del tejido mesenquimático.

Destino del epitelio palatino medio del paladar secundario. El destino del epitelio palatino medio durante la fusión, involucra varios procesos:

- Apoptosis de las células superficiales del periderma.

- Adhesión de las células epiteliales basales para formar una lámina epitelial media.

- Transformación de las células de la lámina epitelial en células mesenquimáticas.

- Migración de las células epiteliales de los extremos de la lámina, a los epitelios oral y nasal.

La muerte celular programada o apoptosis de la lámina epitelial media fue propuesta originalmente por dife-

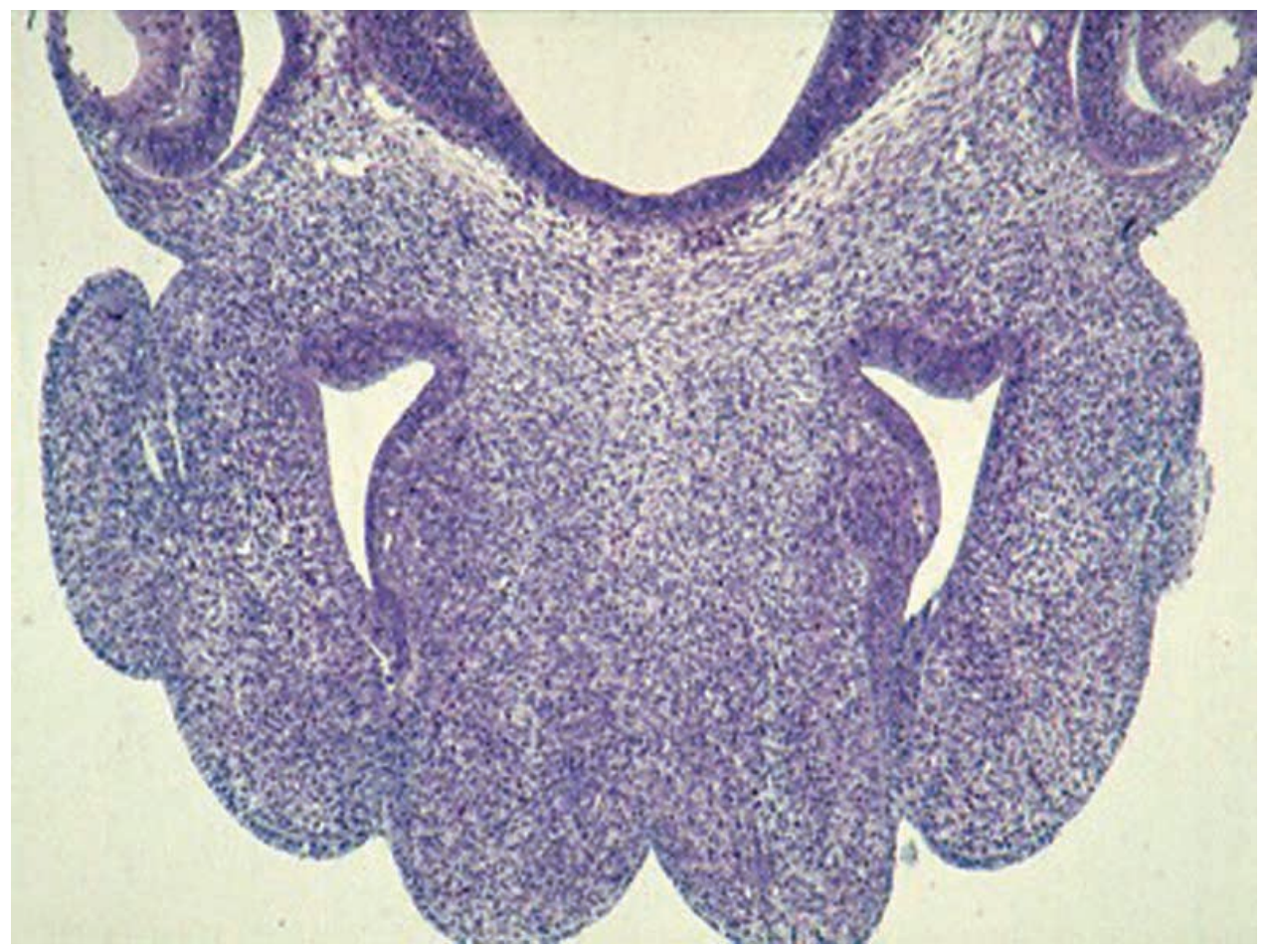

Fig. 6. Corte coronal de cara de embrión de ratón que muestra la lámina epitelial media entre los procesos maxilares y nasales medios. Tinción: H-E. 40X 
rentes investigadores al observar ciertas características en las células epiteliales que se podían considerar como un preludio de muerte celular, como la síntesis de enzimas líticas, correlacionada con la apariencia ultraestructural de lisosomas en las células epiteliales.

Sin embargo, en 1992, Shuler et al. (de la Universidad de Southern California en los Angeles) y Elizabeth Hay et al., (del Harvard Medical School de Boston) demostraron que no todas las células morían, sino que algunas se transformaban en células mesenquimáticas (Hay, 1995). Carette y Ferguson (de la Universidad de Manchester), que ya había postulado la TEM, presentó evidencias que otras células también permanecen viables pero con un fenotipo epitelial y que migran hacia los epitelios oral y nasal vecinos, integrándose a ellos como células epiteliales (Shuler et al., 1992; Hay; Carette y Ferguson, 1992; Ferguson).

Los mecanismos involucrados en estos procesos serían diferentes y por lo tanto podrían ser afectados de manera diferente por la acción de teratógenos.

La técnica del TUNEL confirmó que la apoptosis ocurre sólo en las células peridérmicas. La apoptosis sólo contribuye a la fusión palatina removiendo el periderma para un contacto más eficiente entre las células basales (Nawshad et al.).

Inmediatamente antes de la adherencia, se necesita remover el periderma, para que se formen uniones entre las células basales opuestas. Los desmosomas forman una fusión fuerte, con presencia de caderina-E.

Los mecanismos relacionados con la adhesión epitelial recién se están conociendo. La adhesión inicial está relacionada con la aparición de ciertos cambios en la superficie epitelial justo antes del contacto. En la superficie apical del epitelio palatino medio, aparecen protuberancias, filopodios y un coat formado por el proteoglicano de condroitínsulfato (CSPG), que permite aumentar la adhesión entre los procesos, pero sólo inmediatamente antes del contacto (Martinez-Alvarez et al., 2000a y 2000b; Gato et al., 2002).

La adhesión se modifica fuertemente si se altera la síntesis de CSPG in vitro, con inhibidores como el B-xiloside o con su digestión específica con condroitinasa AC.

La transformación epitelio-mesénquima (TEM) se evaluó con marcadores para seguir linajes celulares con microscopía óptica y electrónica como son los colorantes vitales DIL y carboxyfluoresceina, combinados con técnicas inmunohistoquímicas y estudios ultraestructurales (Carette \&Ferguson; Shuler et al.; Hay).
Durante la TEM las células pierden sus uniones celulares, degradan la lámina basal y protruyen a través de ella. Extienden numerosos filopodios desde su superficie basal hacia el mesénquima subyacente, se amplían los espacios entre ellas y adoptan la morfología de fibroblasto. Dejan de expresar citoqueratinas y empiezan a sintetizar vimentina. Esto incluye producción de metaloproteinasas para remover la lámina basal (Montenegro \& Rojas, 2001).

Función del TGFß-3 en la formación del paladar secundario. Desde hace varios años se conoce que el TGFß-3 (factor de crecimiento transformante $\beta-3$ ) tiene un papel esencial en la palatogénesis, debido a que en ratones transgénicos, del tipo knockout que tienen el gen TGFß-3 no funcional, el paladar no se fusiona (Brunnet et al., 1995; Taya, et al., 1999). Así también, el tratamiento de paladares de ratón con antisense para TGFß-3 o con anticuerpos neutralizantes, inhiben la fusión (Koo et al., 2001).

Normalmente, el paladar de pollo no se fusiona, porque carece de TGFß-3. Sin embargo, la fusión ocurre in vitro, si se agrega TGFß-3 al medio de cultivo, es decir, el TGFb3 induce TEM y confluencia mesenquimática en procesos palatinos de pollo nulos para este factor de crecimiento (Sun et al., 1998).

En el paladar de pollo tratado con TGFß-3, la fusión es similar a lo que ocurre en el paladar de ratón rico en TGFß3 e involucra 2 eventos:

- Adherencia de los epitelios medios para formar una lámina epitelial con desmosomas y CSPG.

- Transformación epitelio-mesenquimática de la lámina epitelial.

En la fusión de los procesos que forman el labio ocurre la misma secuencia.

Existen 3 isoformas de TGF- $\beta$ altamente conservadas entre las especies, (ya que tienen secuencia idéntica de pares de bases en un $75 \%$ y señales a través del factor de transcripción Smads), Sin embargo, los fenotipos resultantes de los knockout de estos mamíferos de las distintas isoformas, son muy distintos, lo que indica que los ligandos tienen actividades específicas que no pueden ser compensados por otros miembros de la familia.

La inhibición del TGFß-1 y TGFb-2 no afectan la transformación epitelio-mesenquimática en el paladar de ratón. El ratón knockout para TGFb-1 muere antes de los 11 días de gestación y el del TGFß-2 tiene defectos en la mandíbula y maxila, con sólo $23 \%$ de fisura palatina. 
TGFß-1 y 3 son epiteliales. El TGFß-3 se detecta en el epitelio de los procesos palatinos desde los inicios y persiste hasta que el epitelio desaparece. El TGFß-2 se expresa en el mesénquima (Cui \& Shuler, 2000).

La presencia del TGFß-3 es fundamental para la confluencia del paladar secundario. Sin embargo, en el pollo y ratón, ningún TGF-b está presente en la lámina epitelial del labio y es capaz de experimentar transformación epiteliomesenquimática (Kaartinen et al., 1997). Al parecer, en este caso, actuarían otros factores presentes en el epitelio, como el factor de transcripción Shh (Sonic hedgehog), ya que su exceso estimula el crecimiento de los procesos maxilares y nasales y su neutralización, inhibe su crecimiento. Además, el ratón mutante nulo para TGFß-3, que tiene paladar fisurado, carece de CSPG y tienen menos prominencias y filopodios, pero si se agrega TGFß-3 a estos procesos palatinos de ratón mutante en cultivo, éstos aparecen junto con la adhesión.

TGFß-3 tiene la función más importante en la fusión palatina y en la transformación epitelio-mesenquimática, mientras que TGFß-2 estimula la síntesis de ADN y la proliferación en el mesénquima, desde las etapas tempranas del desarrollo del paladar.

TGFß-1 es un potente inductor de apoptosis y es posible que ese sea su rol aquí en el periderma. Sería un buen candidato para esa función.

TGFß-3 estimula la fosforilación del factor de transcripción Smad-2, a través de un receptor específico y una vez fosforilado, entra al núcleo para regular positivamente la síntesis y activación del factor de transcripción LEF-1 (lymphoid-enhancing factor) (Nashad \& Hay, 2003).

LEF-1 activa los genes necesarios en la transformación epitelio-mesenquimática, como Snail que reprime la expresión de caderina-E (Savagner et al., 1997; Cano et al., 2000; Martínez-Alvarez et al., 2004).

El ratón knockout para TGFß-3 no tiene labio leporino, solo fisura del paladar secundario. Por lo tanto la ocurrencia de fisura labio-palatina combinada en humanos, no es debida a un solo gen (tal como el TGFb-3 o el Shh) sino que a una serie más compleja de eventos.

Función del Shh y de la BMP en la formación del labio y del paladar primario. Algunos factores implicados en el desarrollo facial incluyen Shh (sonic hedgehog), un factor de transcripción, miembro de la familia hedgehog y BMP (proteína morfogenética de hueso), un factor de crecimiento, miembro de la superfamilia de TGFb.
En el pollo, se ha observado que Shh es esencial para el crecimiento y desarrollo de los esbozos faciales, ya que su bloqueo, inhibe el crecimiento del esbozo facial, mientras que la sobreexpresión de Shh induce crecimiento facial por aumento de la proliferación celular (Hu \& Helms, 1999).

Shh se expresa en el epitelio de los procesos maxilares, procesos nasales medios y en el extremo anterior de los procesos palatinos, en el momento de la fusión del labio.

En el ratón, también se ha detectado expresión de Shh en el epitelio palatino pero su función no es tan clara, ya que ratones deficientes de Shh exhiben holoprosencefalia, con casi completa falta de estructuras esqueléticas faciales.

La holoprosencefalia es resultado de mutaciones del gen Shh, el cual normalmente induce la formación de varias estructuras en la línea media del prosencéfalo. Esta anomalía presenta grados variables de ciclopia, ojos muy juntos, nariz proboscídea, cabeza pequeña y labio leporino.

El Shh es regulado negativamente por dosis teratogénicas de ácido retinoico, ya que el exceso de ácido retinoico tiene un efecto inhibitorio en el Shh del labio (Helms et al., 1997).

Los transcriptos de la proteína morfogenética de hueso, BMP-2 y 4, también se han detectado en los procesos palatinos de ratón, pero no se sabe su función en los mutantes, ya que éstos mueren antes de la formación del paladar (Gong \& Guo, 2003).

El Shh derivado del epitelio medio, activa la expresión de BMP-2 en el mesénquima, la que estimula la proliferación celular.

Función del factor de transcripción Msx-1 en la fusión del labio y paladar. Otro factor importante en el desarrollo de la región cráneo-facial, es el factor de transcripción Msx1 , producto de un gen homeobox, ya que ratones deficientes de Msx-1 exhiben letalidad neonatal y severas anomalías cráneo-faciales, incluyendo fisura palatina y detención del desarrollo dentario en etapa de yema.

En el ser humano, las mutaciones del gen MSX-1, homólogo al Msx-1 del ratón, están asociadas con fisura palatina aislada, no sindrómica y agenesia dentaria, y esto es consistente con el fenotipo observado en ratones (deficientes Msx-1). Los procesos palatinos se forman, se elevan normalmente pero no hacen contacto y nunca se fusionan (Alappat et al., 2003).

La expresión de Msx-1 está restringida a la región 
anterior del mesénquima de los procesos palatinos y de los procesos faciales. Msx-1 es necesario para la expresión de BMP 2 y 4 en el mesénquima y de Shh en el epitelio.

Horizontalización de los procesos palatinos. Otro momento crítico en el desarrollo del paladar secundario, es la rotación de los procesos palatinos desde una posición vertical a ambos lados de la lengua, a una posición horizontal sobre ella para fusionarse.

Las investigaciones actuales indican que éste es un cambio brusco, que igual que la fusión tampoco ocurre simultáneamente a lo largo del paladar.

Este cambio es resultado de una fuerza intrínseca, generada principalmente por acumulación progresiva e hidratación de ácido hialurónico. Cuando esta fuerza alcanza cierto nivel que excede la resistencia funcional de la lengua, ocurre el cambio de posición. Esta fuerza elevadora es ayudada por manojos de colágeno tipo I, cuya síntesis aumenta durante la reorientación.

Durante el período de la elevación, casi no hay crecimiento en el ancho de la cabeza, pero si un constante crecimiento en la altura de la cabeza. Además, los músculos de la lengua se hacen funcionales en este período y también hay reflejos fetales. Los embriones humanos empiezan a hipar, pero todavía no hay apertura de la mandíbula, ni deglución, ni succión, hasta después del cierre del paladar (Palomino \& Montenegro).

Factores que condicionan la susceptibilidad a la fisura palatina. Los glucocorticoides son teratogénicos en algunos roedores de laboratorio, como ratón y hamster. Cuando se administra una dosis durante una etapa precisa de la gestación, se produce un significativo aumento de fisura palatina en la descendencia. Pero igual a lo que sucede en el hombre, ratones de distintas cepas, presentan diferente susceptibilidad a la fisura palatina al ser inducida por una dosis estandar de glucocorticoides (Fig. 7).

Los glucocorticoides inhiben la síntesis de TGFb-3 de una manera dosis-dependiente pero no tienen efecto sobre las otras 2 isoformas de TGFß. También inhiben la síntesis de ácido hialurónico, entre otros efectos.

¿Dónde radica la susceptibilidad entre cepas de ratones o entre diferentes grupos raciales humanos?

Algunos trabajos experimentales han demostrado que las diferencias en la expresión de algunas moléculas determinantes del desarrollo normal, como el ácido hialurónico o TGFb-3 serían responsables de la diferente susceptibilidad y esta expresión se debería a una actividad génica diferencial.

Utilizando técnicas inmunohistoquímicas, cultivo in vitro y métodos computacionales con registro de imágenes, para comparar la distribución de algunas moléculas basado en la intensidad de la tinción, encontramos diferencias significativas en la expresión de algunas queratinas y caderinaE en el epitelio palatino medio y en el ácido hialurónico de la matriz extracelular de los procesos palatinos, en las dos cepas, en etapas críticas del desarrollo. Otras moléculas analizadas como colágeno y fibronectina, no mostraron diferencias (Montenegro et al., 1998, 2000).

Usando esta aproximación, es posible ir desde la descripción morfológica del desarrollo de la cara y del paladar, a un análisis celular y molecular de los mecanismos involucrados y entonces identificar los genes candidatos que pueden ser importantes para screening y diagnóstico de las fisuras labio-palatinas.

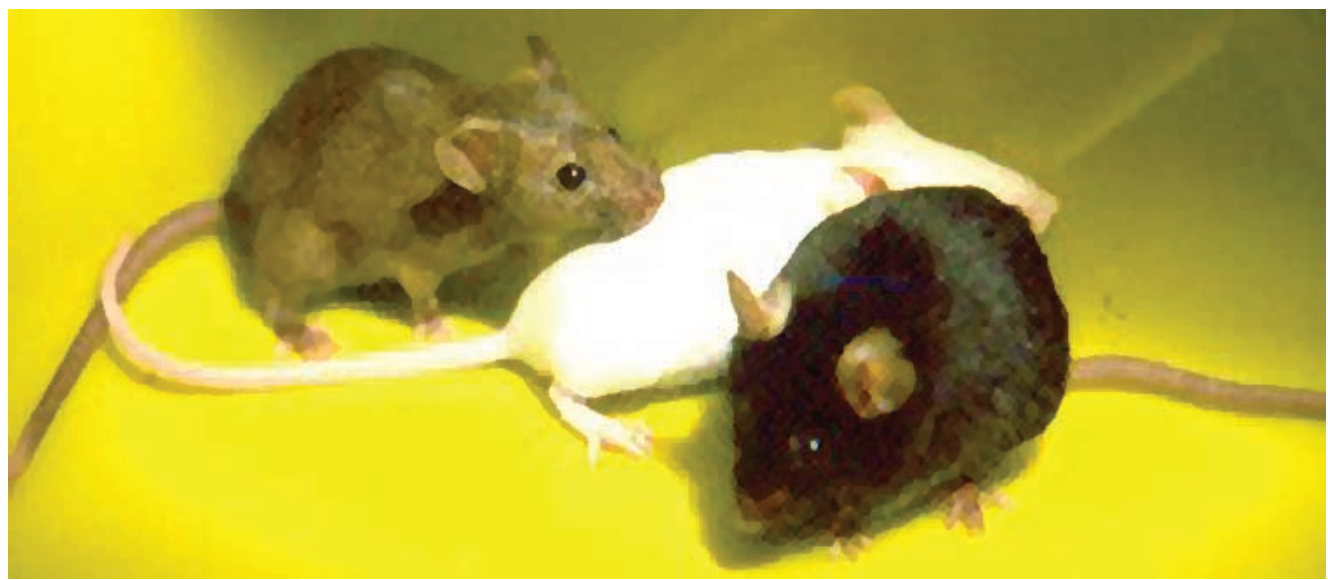

Fig. 7. Ratones que presentan diferente susceptibilidad a la fisura labio-palatina. Cepa A/Snell susceptible (ratón blanco) y cepa B/10 resistente (ratón negro). Ratón gris es híbrido que será susceptible si su madre es susceptible y resistente si su madre es resistente. 
MONTENEGRO, M. A. \& ROJAS, M. Molecular basis on the face and palate developmentr. Int. J. Morphol., 23(2):185-194, 2005.

SUMMARY: In mammals, the adhesion and fusion of the facial and palatal shelves are essential mechanisms in the development of the primary and secondary palate. Failure of any of these processes leads to the formation of cleft lip and palate. In both cases, the opposing shelves adhere to each other by desmosomes to form an epithelial seam which disappears by epithelial-mesenchymal transformation. Apoptosis occurs only in the periderm. In the palate, these processes are regulated by TGFß-3, but in the face this growth factor is not present in maxilar and nasal shelves and in lip formation would act other factors, such as Shh and BMP that have been shown to be involved in avian lip confluence.

KEY WORDS: Mouse palate; Avian lip; TGFß-3; Shh; Epithelial-mesenchymal transformation; Epithelial seam.

\section{REFERENCIAS BIBLIOGRÁFICAS}

Alappat, S.; Zhang, Z. Y. \& Chen, Y. P. Msx homeobox gene family and craniofacial development. Cell Res., 13:429-42, 2003.

Brunnet, C. L.; Sharpe, P. M. \& Ferguson, M. W. J. Inhibition of TGFß-3, (but not TGFß-1 or TGFß-2) activity prevents normal mouse embryonic palate fusion. Int. J. Dev. Biol., 39:345-55, 1995.

Cano, A.; Perez-Moreno, M. A.; Rodrigo, I.; Locascio, A.; Blanco, M. J. \& del Barrio, M.G. The transcription factor Snail controls epithelial-mesenchymal transitions by repressing E-cadherin expresión. Nat. Cell Biol., 2:76$83,2000$.

Carette, M. J. \& Ferguson, M. W. J. The fate of medial edge epithelial cells during palatal fusion in vitro. An analysis by DIL labeling and confocal microscopy. Development, 114:379-88, 1992.

Cui, X. M. \& Shuler, C. F. The TGF-beta type III receptor is localizad to the medial edge epithelium during palatal fusion. Int. J. Dev. Biol., 44:397-402, 2000.

Ferguson, M. W. J. Palate development. Development 103:41-60, 1988.

Ferguson, M. W. J. Craniofacial malformations. Towars a molecular understanding. Nat. Genet., 6:329-30, 1994.

Ferguson, M. W. J.; Honig, L. S. \& Slavkin, H.C. Differentiation of cultured palatal shelves from Alligator, chick, and mouse embryos. Anat. Rec., 209:231-49, 1984.

Gato, A.; Martinez, M. L.; Tudel, I.; Alonso, I.; Moro, J. A. \& Formoso, M.A., Ferguson, M. W. J. \& MartinezAlvarez, C. TGFß-3-induced chondroitin sulphate proteoglycan mediates palatal shelf adhesión. Dev. Biol., 250:393.405, 2002.
Gong, S. G. \& Guo, C. BMP4-gene is expressed at the putative site of fusion in the midfacial region. Differentiation, 71:228-36, 2003.

Hay, E. D. An overview of epithelio-mesenchymal transformation. Acta Anat., 154:8-20, 1995.

Helms, J. A.; Kim, C. H.; Minkoff, R.; Thaller, C. \& Eichele, G. Sonic hedgehog participates in craniofacial morphogenesis and is down-regulated by teratogenic doses of retinoid acid. Dev. Biol., 187:25-35, 1997.

Hu, D. \& Helms, J. A. The role of Sonic hedgehog in normal and abnormal craniofacial morphogenesis. Development, 126:4873-84, 1999.

Kaartinen, V.; Cui, X. M.; Heisterkamp, N.; Groffen, J. \& Shuler, C. F. TGFß-3 regulates transdifferentiation of medial edge epithelium during palatal fusion and associated degradation of basement membrane. Dev. Dynamics, 209:255-60, 1997.

Koo, S. H.; Cunningham, M. C.; Arabshahi, B.; Grass, J. S. \& Grant, J. H. The transforming growth factor-beta 3 knockout mouse: an animal model for cleft palate. Plast. Reconstr. Surg., 108:938-48, 2001.

Martinez-Alvarez, C.; Tudela, C.; Perez-Miguelsanz, J. O”Kane, S.; Puerta, J. \& Ferguson, M.W.J. Medial edge epithelial cell fate during palatal fusion. Dev. Biol. 220:343-57, 2000a.

Martinez-Alvarez, C.; Bonelli, R.; Tudela, C.; Gato, A.; Mena, J.; O”Kane, S. \& Ferguson, M. W. J. Bulging medial edge epithelial cells and palatal fusion. Int. J. dev. Biol., 44.331-35, 2000b.

Martinez-Alvarez, C.; Blanco, M. J.; Parez, R.; Rabadán, M. A.; Aparicio, M. \& Ferguson, M. W. J. Snail family 
members and cell survival in physiological and pathological cleft palates. Dev. Biol., 265:207-18, 2004.

Montenegro, M. A.; Rojas, M. A.; Domínguez, S. \& Rosales, C. J. Differences in extracellular matrix components and cell density during normal and dexamethasonetreated secondary palate development in two strains of mice with different susceptibility to glucocorticoidinduced clefting. J. Craniofac. Gen. Dev. Biol., 18:10006, 1998.

Montenegro, M. A.; Rojas, M. A.; Domínguez, S. \& Vergara, A. Cytokeratin, vimentin and E-cadherin immunodetection in the embryonic palate in two strains of mice with different susceptibility to glucocorticoidinduced clefting. J. Craniofac. Gen. Dev. Biol., 20:13743, 2000.

Montenegro, M. A. \& Rojas, M. A. Transformación epitelio-mesenquimática durante el desarrollo embrionario. Rev. Chil. Anat., 19:301-10, 2001.

Nashad, A. \& Hay, E. D. TGFß-3 signaling activates transcription of the LEFT1 gene induce epithelial mesenchymal transformation during mouse palate. Development, 63:1291-301, 2003.

Nawshad, A.; LaGamba, D. \& Hay, E.D. Transforming growth factor $B$ (TGFß) signaling in palatal growth, apoptosis and epithelial mesenchymal transformation (EMT). Archs. Oral Biol., 49:675-89, 2004.

Palomino, H. M.; Palomino, H.; Cauvi, D.; Barton, S. \& Chakraborty, R. Facial clefting and amerindian admixture in populations of Santiago, Chile. Am. J. Human Biol., 9:225-32, 1997.

Palomino, H. \& Montenegro, M. A. Genes y moléculas en el desarrollo cráneo-facial. Rev. Chil. Ortod., 19:20-31, 2002.

Savagner, P.; Yamada, K. M. \& Thiery, J. P. The zinc finger protein Slug causes desmosome dissociation, an initial and necessary step for growth factor-induced epithelialmesenchymal transition. J. Cell Biol., 137:1403-19, 1997.

Shuler, C. F.; Halpern, D. E.; Guo, Y. \& Sank, A. C. Medial edge epithelium fate traced by cell lineage analysis during epithelial-mesenchymal transformation in vivo. Dev. Biol., 154:318-30, 1992.

Sun, D.; Vanderburg, C. R.; Odierma, G. S. \& Hay, E. D.
TGFß-3 promotes transformation of chicken palate medial edge epithelium to mesenchyme in vitro. Development, 125:95-105, 1998.

Sun, D.; Baur, S. \& Hay, E. D. Epithelial-mesenchymal transformation is the mechanism for fusion of the craniofacial primordia involved in morphogenesis of the chicken lip. Dev. Biol., 228:337-49, 2000.

Taya, Y.; O"Kane, S. \& Ferguson, M.W. J. Pathogenesis of the cleft palate in TGF-B3 knockout mice. Develoment, 126:3869-79, 1999.

Dirección para correspondencia:

Prof. Dra. María Angélica Montenegro

Laboratorio de Embriología Comparada

Programa de Anatomía y Biología del Desarrollo

Instituto de Ciencias Biomédicas

Facultad de Medicina

Universidad de Chile

Independencia 1027,

Santiago - CHILE

Fax: $\quad 56-2-6786264$

Fono: 56-2-678 6261

E-mailmmontene@med.uchile.cl

Recibido: 16-01-2005

Aceptado: 30-04-2005 